\section{Research Square}

Preprints are preliminary reports that have not undergone peer review.

They should not be considered conclusive, used to inform clinical practice, or referenced by the media as validated information.

\title{
Association of Antenatal Corticosteroid Administration-to-delivery Interval With Neonatal Respiratory Distress Syndrome and Respiratory Support in Preterm Infants
}

\author{
Lixia Li ( $\nabla$ travellerlilixia@163.com ) \\ Shaoxing Maternity and Child Health Care Hospital \\ Haijing Li \\ Shaoxing Maternity and Child Health Care Hospital \\ Yejun Jiang \\ Shaoxing Maternity and Child Health Care Hospital

\section{Beimeng Yu} \\ Shaoxing Maternity and Child Health Care Hospital \\ Xiuren Wang \\ Shaoxing Maternity and Child Health Care Hospital \\ Wujiang Zhang \\ Shaoxing Maternity and Child Health Care Hospital
}

\section{Research Article}

Keywords: Antenatal corticosteroid, Neonatal morbidity, Respiratory distress syndrome, ACS-to-birth interval

Posted Date: January 11th, 2022

DOI: https://doi.org/10.21203/rs.3.rs-1158012/v1

License: () (1) This work is licensed under a Creative Commons Attribution 4.0 International License. Read Full License 


\section{Abstract}

Background: Administration of antenatal corticosteroids (ACS) is an effective strategy for the management of preterm infants, which can improve neonatal respiratory distress syndrome (NRDS) and attenuate the risk of neonatal mortality. However, many preterm infants do not expose to a complete course of ACS administration, and the effects of different ACS-to-delivery intervals on NRDS and respiratory support remain unclear.we explore the relationships of ACS administration-to-birth intervals with NRDS and respiratory support in preterm infants in this study.

Methods: In this retrospective cohort study, the preterm infants born between $24^{0 / 7}$ and $31^{6 / 7}$ wk of gestation were recruited from Jan 2015 to Jul 2021 . All participants were categorized based on the time interval from the first ACS dose to delivery: $<24 \mathrm{~h}, 1-2 \mathrm{~d}, 2-7 \mathrm{~d}$, and more $>7 \mathrm{~d}$. Multivariable logistic regression analysis was conducted to examine the relationships between ACS-to-birth interval and primary or secondary outcome, while adjusting for potential confounders.

Results: Of the 706 eligible neonates, 264, 83, 292 and 67 received ACS-to-delivery intervals of $<24$ h, 1-2 d, 2-7 d and $>7$ d, respectively. After adjusting these confounding factors, multivariable logistic analysis showed a significant increased risk of NRDS (aOR: 1.8, 95\% Cl: 1.2-2.7), neonatal mortality (aOR: 2.8, 95\% $\mathrm{Cl}$ : 1.1-6.8), the need for surfactant use (aOR: $2.7,95 \% \mathrm{Cl}: 1.7-4.4)$, endotracheal intubation in delivery room (aOR: 1.9, 95\% Cl: 1.0-3.7), mechanical ventilation (aOR: $1.9,95 \% \mathrm{Cl}: 1.1-3.4$ ) in the ACS-to-delivery interval of <24 h group when compared with the ACS-to-birth interval of 2-7 d group. Similar findings were observed in the subgroup analysis of the ACS interval of $<6 \mathrm{~h}$ and $6-12 \mathrm{~h}$ groups (incidence of death and surfactant use), but no obvious differences were found in the ACS intervals of 12-24 h, 1-2 d and >7 d groups compared with the ACS-to-birth interval of 2-7 d group.

Conclusions: Neonatal outcomes such as NRDS, neonatal mortality, the need for surfactant use, intubation in delivery room, mechanical ventilation are at a higher risk when the neonates exposed to ACS interval for less than $12 \mathrm{~h}$ before delivery.

\section{Background}

Neonatal respiratory distress syndrome (NRDS) is a common problem in premature neonates due to inadequate surfactant activities in the immature fetal lungs, which is the most common cause of respiratory failure in the first few days after birth, thus resulting in neonatal death. Administration of antenatal corticosteroids (ACS) is an effective treatment strategy for pregnant women at high risk of preterm birth. It accelerates lung maturation and reduces the incidence of NRDS. Therefore, a full course of ACS may be recommended between 24 and 34 wk of pregnancy for women who are at risk of preterm labor [14]. Previous studies showed that the incidence of NRDS and the rate of neonatal mortality were significantly reduced after a complete course of ACS [5-9], while the effect of ACS on the need for respiratory support in delivery room and neonatal intensive care units (NICU) among preterm infants has been sparsely investigated. The effect of a single course of ACS appears more pronounced when a premature birth occurs between 2 and $7 \mathrm{~d}$, and its effectiveness is markedly declined at the ACS-to-birth intervals of less than $48 \mathrm{~h}$ and exceeded $7 \mathrm{~d}$ [10-15]. In contrast, women admitted in pre-active labor tended not to receive ACS or only received a partial course of ACS before delivery. A study found that only $40.7 \%$ of infants received ACS $1-7 \mathrm{~d}$ before delivery, and $24.2 \%$ of infants received ACS less than $24 \mathrm{~h}$ before delivery [6]. A retrospective analysis of Canadian Neonatal Network data revealed that $41.5 \%$ of infants did not exposed to a complete course of ACS [12]. However, whether exposure to ACS at different time intervals can affect the risk of bronchopulmonary dysplasia (BPD) and neonatal death as well as the need for endotracheal ventilation at birth, mechanical ventilation and surfactant administration remains largely unclear. Moreover, the effects of different ACS-to-birth intervals on NRDS and respiratory support(intubated-mechanical ventilation) have not been adequately studied, particularly within the ACS-to-birth intervals of $<24 \mathrm{~h}$. Hence, this study aimed to determine the effects of different ACS-to-delivery intervals on NRDS and the need for respiratory support in preterm infants, and to determine the optimal timing of ACS administration before preterm birth.

\section{Materials And Methods Study design and subjects}

In this retrospective cohort study, the preterm infants born between $24^{0 / 7}$ and $31^{6 / 7} \mathrm{wk}$ of gestation were recruited from Jan 1 st, 2015 to Jul 31 st 2021 in Shaoxing Maternity and Child Health Care Hospital, a tertiary hospital in Zhejiang Province. Gestational age (GA) was described by ultrasonography before 20 wk of pregnancy or the first day of the woman's last menstrual period. Inclusion criteria were infants who were inborn and transferred to neonatal intensive care units (NICU) within $2 \mathrm{~h}$ after birth with $\mathrm{GA}<32 \mathrm{wk}$. Delivery room death or infants who were not admitted to NICU or discharged from the hospital due to high cost burden to family members were not included in our study. Those who were outborn, admitted to NICU after $2 \mathrm{~h}$ of birth, had major congenital malformations, non-exposure to ACS or repeated use of ACS before delivery were also excluded from this study. The ethical approval for this study was obtained from the hospital research and ethics committee.

\section{Exposure and outcomes}

A complete course of ACS is defined as the intramuscular administration of $6 \mathrm{mg}$ dexamethasone every $12 \mathrm{~h}$ for up to four doses. The interval was determined from the first ACS dose to delivery. All infants were categorized into four groups as follows: $<24 \mathrm{~h}, 1-2 \mathrm{~d}, 2-7 \mathrm{~d}$, and $>7 \mathrm{~d}$. In the subgroup analysis,the ACS-tobirth interval of $<24 \mathrm{~h}$ was divided into 3 groups: $<6 \mathrm{~h}, 6-12 \mathrm{~h}$ and $12-24 \mathrm{~h}$, respectively. Maternal and infant health data were acquired from the electronic medical records. The maternal data included maternal age, ACS-to-birth interval (hours from the first ACS dose to delivery), mode of delivery, maternal complications such as gestational diabetes mellitus, gestational hypertension (e.g., gestational hypertension and pre-eclampsia), placental abruption, placenta previa, preterm prelabor rupture of membranes (PPROM) $>18 \mathrm{~h}$, oligohydramnios and fetal intrauterine distress. The neonatal data such as GA at birth, gender, birth weight, multiple births, the need for endotracheal intubation in delivery room, BPD (defined as the need for respiratory support or supplemental oxygen at 36 wk post-menstrual age) [16], NRDS [diagnosed by chest radiography and at least clinical sign of respiratory distress (e.g., 
respiratory grunting, retracting, etc.) and increased oxygen requirement (fraction of inspired oxygen of greater than 0.3) or the administration of exogenous pulmonary surfactant] [11], the need for pulmonary surfactant (both in delivery rooms and in NICU), the need for intubation/mechanical ventilation, the duration of ventilatory support (invasive or non-invasive), the duration of stay in hospital and neonatal mortality (defined as death before discharge) were collected. Intubation/mechanical ventilation included high-frequency and conventional ventilation. Non-invasive respiratory support included non-invasive positive pressure ventilation, non-invasive high-frequency ventilation, high-flow oxygen, and nasal continuous positive airway pressure.

The primary outcome was the overall incidence of mild, moderate or severe NRDS. The secondary outcomes included the need for pulmonary surfactant use, intubation/mechanical ventilation, BDP, the need for intubation in delivery room, duration of ventilatory support, duration of stay in hospital (days), and neonatal mortality.

\section{Statistical analyze}

Data were expressed as median (interquartile range, IQR) for variables that did not follow a normal distribution, mean \pm standard deviation (SD) for normally distributed data, or frequencies for categorical variables. The baseline characteristics were compared with Kruskal-Wallis $\mathrm{H}$ test for continuous variables with non-normal distribution, or one-way ANOVA for those with normal distribution. Categorical variables were compared with chi-square test. The relationships between ACS-to-delivery intervals and respiratory outcome rates were assessed by univariate and multivariate logistic regression analyses. For the multivariate analysis, the covariates used were as follows: birth weight, GA at birth, delivery mode, premature rupture of membranes $>18 \mathrm{~h}$, placenta previa and hypertension disorders in pregnancy. The infants exposed to ACS within 2-7 d before birth were regarded as a reference group. A subgroup analysis of the association between ACS-to-birth interval of $<24 \mathrm{~h}$ and neonatal pulmonary outcomes was also performed by multiple logistic regression model using the same reference group. All statistical tests was conducted with STATA 15.0. Odds ratio (OR) and $95 \%$ confidence interval (CI) were estimated for binary outcomes. A two-sided $p$-value of $<0.05$ was regarded as statistically significant.

\section{Results}

\section{Characteristics of the study population}

A total of 861 infants were delivered between $24^{0 / 7}$ and $31^{6 / 7}$ wk of gestation. Neonates with major neonatal malformations or congenital disease ( $n=2$ ), admitted to NICU after $2 \mathrm{~h}$ of birth $(n=11)$, not admitted to NICU $(n=53)$, discharged from the hospital due to family financial difficulties, or concerns about the prognosis ( $n=43)$ were excluded. Moreover, 6 infants received multiple courses of ACS, 40 infants did not received ACS before birth, and 1 infant whose mother diagnosed as systemic lupus erythematosus were also excluded. Finally, 706 infants were included in the study: 264, 83, 292 and 67 infants were born at the ACS-to-delivery intervals of $<24 \mathrm{~h}, 1-2 \mathrm{~d}, 2-7 \mathrm{~d}$ and $>7 \mathrm{~d}$, respectively (Figure 1).

The maternal infant baseline characteristics are summarized in Table 1. Of the 706 neonates, 66 (9.35\%), 203 (28.75\%) and 437 (61.90\%) were born at the GA of $24-27^{6 / 7}, 28-29^{6 / 7}$ and $30-31^{6 / 7} \mathrm{wk}$, respectively. Women receiving ACS $<24 \mathrm{~h}$ before delivery were less likely to have PPROM $>18 \mathrm{~h}$, placenta previa, hypertension disorder, vaginal delivery and twin, while more likely to have low GA and birth weight. Significant differences in the maternal characteristics such as hypertensive disorders, placenta previa, GA at delivery, PPROM $>18 \mathrm{~h}$, and mode of delivery were observed among the 4 groups (Table 1 ). The incidence of placental abruption, gestational diabetes and fetal intrauterine distress before delivery were relatively similar among the 4 groups. The median duration of ventilation (invasive and non-invasive support) was $10 \mathrm{~d}$ (IQR: $2,23 \mathrm{~d}$ ) in the ACS interval of <24 h group and $4.5 \mathrm{~d}$ (IQR: 1, $13 \mathrm{~d}$ ) in the ACS interval of $>7 \mathrm{~d}$ group $(p=0.01)$. The intervals from the first corticosteroid dose to delivery were remarkably different among the 4 groups, while the lengths of hospitalization were quite similar among the 4 groups (Table 1). Figure 2 shows the distribution of GA at birth for the 4 groups.

\section{Relationships between ACS-to-birth intervals and neonatal outcomes}

The infants exposed to ACS at 2-7 d before birth tended not to use surfactant and require for intubation-mechanical ventilation (17.1\% and 10.3\%) compared to those exposed $<24 \mathrm{~h}(37.1 \%$ and $18.9 \%), 1-2 \mathrm{~d}(18.1 \%$ and $10.8 \%)$ and $>7 \mathrm{~d}(22.4 \%$ and $13.4 \%)$ before delivery, respectively. The unadjusted cumulative incidence rates and ORs testing associations between ACS intervals and neonatal outcomes are shown in Table 2. The unadjusted incidence of NRDS, death, the need for intubation in delivery room, surfactant use and mechanical ventilation were significantly higher in the ACS interval of < $24 \mathrm{~h}$ compared with the administration-to-birth interval of 2-7 d. There was no difference in the incidence of BPD among the 4 groups.

After adjusting these confounding factors, multivariable logistic regression analysis revealed the significantly increases in NRDS risk (aOR: 1.8, 95\% Cl: 1.22.7), mortality rate (aOR: $2.8,95 \% \mathrm{Cl}$ : 1.1-6.8), the need for surfactant use (aOR: 2.7, 95\% Cl: 1.7-4.4), the need for endotracheal intubation at birth (aOR: 1.9 , $95 \% \mathrm{Cl}: 1.0-3.7)$, intubation/mechanical ventilation rate (aOR: 1.9, 95\% Cl: 1.1-3.4) and surfactant use or intubation/mechanical ventilation rate (aOR, 2.8 ; $95 \%$ $\mathrm{Cl}, 1.7-4.4$ ) in the ACS-to-birth interval of <24 h group compared with the ACS-to-birth interval of 2-7 d group (Table 2). Compared with the ACS-to-birth interval of 2-7 d group, the rates of NRDS, surfactant use, intubation/mechanical ventilation and mortality were relatively similar in the ACS intervals of 1-2 $d$ and $>7 \mathrm{~d}$ groups (Table 2). However, no remarkable difference in the rate of BPD was found among the 4 groups after adjusting the variables.

\section{Subgroup analysis for the association between ACS-to-birth interval of $<24 \mathrm{~h}$ and neonatal pulmonary outcomes}

Of the 264 neonates exposed to ACS <24 h before birth, 153 (23.9\%), 50 (7.8\%) and 61 (9.6\%) were born <6 h, 6-12 h and 12-24 h, respectively. After adjusting those confounding factors, the incidence of NRDS, mortality rate, surfactant use, intubation in delivery room, rate of intubation/mechanical ventilation (aOR: 
$2.8,95 \% \mathrm{Cl}: 1.5-5.4)$ and rate of surfactant use or mechanical ventilation were significantly higher in neonates delivered $<6 \mathrm{~h}$ after ACS exposure than in those delivered within 2-7 d after ACS exposure (Table 3). Moreover, the rates of mortality, surfactant use, mechanical ventilation or surfactant use were significantly increased in the ACS-to-birth interval of 6-12 h group compared with the ACS-to-birth interval of $<6 \mathrm{~h}$ group. However, the rates of BPD were not remarkably different among the 4 groups.

\section{Discussion}

\section{Main findings of the study}

In the present study, we assessed the effects of different ACS-to-delivery intervals on NRDS incidence and respiratory support in preterm infants ( $\mathrm{n}=706$ ). Approximately $49.15 \%$ of preterm infants did not receive a complete course of ACS, while $37.39 \%$ of preterm infants received ACS at an interval of < $24 \mathrm{~h}$. Our findings demonstrated that the infants with the ACS-to-delivery interval of $<24$ had a higher risk of NRDS, neonatal mortality, the need for surfactant use and mechanical ventilation when compared to those the ACS-to-delivery interval of 2-7 d. Administration of ACS $>7 \mathrm{~d}$ before delivery was not significantly associated with an increased risk of those complications compared with the infants who exposed to ACS 2-7 d before delivery. The subgroup analysis indicated a significantly higher rate of the need for respiratory support among infants who exposed to ACS within $12 \mathrm{~h}$ before delivery, especially within $6 \mathrm{~h}$.

\section{Comments on the results}

The incidence of NRDS, death, surfactant use, the need for mechanical ventilation and intubation in delivery room were significantly higher in the ACS-to-birth interval of $<24 \mathrm{~h}$ group than in the ACS-to-birth interval of 2-7 d group. These results are in good agreement with those of previous studies reporting on the effects of ACS-to-birth intervals on neonatal morbidity. ${ }^{10-15}$ We found that the ACS-to-birth interval of $<6 \mathrm{~h}$ could increase the rates of neonatal mortality and respiratory support (but not BPD). Moreover, the occurrence of death, the need for surfactant use, and the need for mechanical ventilation or surfactant use were increased in the ACS-to-birth interval of 6-12 h group, but these complications were not apparently found in the ACS-to-birth interval of $>12 \mathrm{~h}$ group.

We first evaluated the association of the ACS-to-birth interval of $<6 \mathrm{~h}, 6-12 \mathrm{~h}$ or $12-24 \mathrm{~h}$ with neonatal mortality and the need for respiratory support. The results showed that the effect of ACS gradually appeared at $6 \mathrm{~h}$ following administration, and full protection could be achieved after $>12 \mathrm{~h}$ of ACS administration. A study of preterm lambs found that the physiological parameters of the respiratory system were improved after $15 \mathrm{~h}$ of a single dose of betamethasone, while no improvements was observed after 8 hour of treatment-to-delivery interval [17]. Hence, the authors suggested that the optimal interval from fetal corticosteroid treatment to delivery was between 8 and $15 \mathrm{~h}$ for improving the postnatal lung functional responses [17], which was consistent with our results. Our findings was also supported by a prospective cohort study of pregnant women with GA between 24 and 31 wk [6]. The study found that the ACS-to-birth interval of $<12 \mathrm{~h}$ was related to a significant decrease in neonatal mortality, while the was no obvious difference in mortality rates between the ACS-to-delivery intervals of $12 \mathrm{~h}$ and $18-48 \mathrm{~h}$ groups. Thus, it is speculated that ACS may be effective even if they are administered a few hours before delivery. In our study, the ACS-to-birth interval of $>12 \mathrm{~h}$ was not related to a high risk of neonatal death and respiratory support. Such findings have not been reported in other studies, which may be attributed to the fact that most studies did not perform subgroup analysis by the ACS-to-delivery intervals of < $24 \mathrm{~h}$ for neonatal mortality and respiratory outcomes.

In a recent retrospective study, Norberg et al [18]. found that extremely preterm infants born $<24 \mathrm{~h}$ after ACS as well as those born more than 7 days after ACS administration had lower HRs for survival ( $\mathrm{HR}=0.53 ; 95 \% \mathrm{Cl}=0.33-0.87$ and $\mathrm{HR}=0.56 ; 95 \% \mathrm{Cl}=0.32-0.97$, respectively) than infants born $48 \mathrm{~h}$ to 7 days after ACS administration. In that study., the survival rate of infants born at $24-47 \mathrm{~h}$ did not differ from that of infants born $48 \mathrm{~h}$ to $7 \mathrm{~d}$ after $\mathrm{ACS}$ administration [18], which was similar to our study. Moreover, the NRDS and respiraorty outcomes were not significantly different between the ACS-to-delivery intervals of 1-2 d and 2-7 d groups, and we did not observe any differences between the ACS-to-delivery intervals of $>7 \mathrm{~d}$ and 2-7 d groups. In another study of Neonatal Research Network of Japan at 24-31 wk gestation, Ushida et al. [19] found that ACS treatment was associated with significant decreases ineneonatal death, NRDS, and IVH in both hypertensive disorders of pregnancy (HDP) and non-HDP groups. which was in line with our study. However, neonates were grouped as exposure to non-exposure to ACS groups, and no further classification was performed in that study. In contrast to our findings, a recent study found no differences in respiratory, cerebral, and composite outcomes for the ACS intervals of $\leq 2 \mathrm{~d}, 2-7 \mathrm{~d}, 8-14 \mathrm{~d}$, and $>14 \mathrm{~d}$ groups [20]. In that study, the percentages of surfactant use and the risk of ventilation were decreased with increasing time intervals [20]. However, the authors only reported association estimates, and did not perform extensive multivariate regression analysis [20]..

Taking account of the pharmacological mechanism of ACS, the fetus can respond differentially to corticosteroids at the primary $(0-24 \mathrm{~h})$ and secondary $(>24$ h) phases compared with the first dose. Studies showed an increase in fetal heart rate (FHR) variability for both dexamethasone and betamethasone at the primary phase, in which antenatal betamethasone increases the expression of $\mathrm{Na}^{+}, \mathrm{K}^{+}$-ATPase and ENaC subunits in the airway and respiratory epithelium, thus contributing to the beneficial pulmonary effects of ACS [21-24]. This may be the reason why its action is more rapidly.

There is conflicting evidence on the effect of the ACS-to-birth interval of $>7 \mathrm{~d}$ on neonatal death. In a large retrospective cohort study of infants born at 24-33 wk of gestation from the Canadian neonatal network, the rates of neonatal morbidity and mortality were significantly higher in the ACS-to-delivery interval of $>7 \mathrm{~d}$ [12]. A secondary analysis of 2259 infants between $23^{0 / 7}$ and $33^{6 / 7}$ wk of gestation showed that the ACS-to-delivery interval of 7-14 d was associated with severe neonatal morbidity, and the risk of severe neonatal morbidity (aOR: 1.57, 95\% Cl: 1.12-2.19) was higher in the ACS-to-birth interval of >14 d group than in the ACS-to-birth interval of 2-7 d group [10]. Another study showed that the twins in the ACS-to-delivery interval of $>7 \mathrm{~d}$ group (39.4\%) had a decreased risk of NRDS (aOR: $2.205,95 \%$ Cl: $0.773-6.292)$ compared to those in the non-exposure group (50.8\%), but the difference was not statistically significant [11]. This may be due to the fact that the transient effect of ACS may persist for a longer time [6,25]. Another possible explanation is the small sample size of our study. Therefore, further multicenter, prospective cohort studies should be carried out in the near future. 
The rates of BPD did not differ significantly among the 4 groups. This could be explained by the fact that the sample size of infants delivered at < 28 wk of gestation ( $\mathrm{n}=66$ ) was relatively small in our study. Moreover, BPD occurs almost exclusively in premature infants (born at $28 \mathrm{wk}$ or less), as they are more vulnerable to lung anomalies in the postnatal environment. The strongest risk factors for BPD are prematurity and low birth weight [26]. Other studies also reported no signification association between BPD and timing of ACS administration [5, 27]. Therefore, the potential relationship between ACS-to-delivery interval and BPD risk needs to be investigated further.

\section{Strength and limitations}

In this study, the ACS-to-delivery intervals (in hours) of preterm infants were acquired without data loss. We assessed the effects of different ACS intervals of $<24 \mathrm{~h}$ on neonatal mortality, which were sparely investigated in previous studies, and the categories had been shown to be more precisely within the ACS interval of $<24 \mathrm{~h}$. The existing evidence on the association between ACS administration and neonatal outcomes is mainly focused on high-income countries and hospital settings in which antenatal betamethasone is primarily applied for perinatal care. However, antenatal dexamethasone is mainly used for perinatal management in developing countries. Therefore, the findings of antenatal dexamethasone-to-delivery interval and neonatal respiratory support are more applicable to preterm birth in developing countries.

There are also several limitations that should be noted. First, the ACS used in our hospital was dexamethasone; thus the results of this study should be interpreted with caution. Second, there is a potential postnatal bias in which some infants did not receive intensive care. To reduce this effect, the infants received no delivery room resuscitation or those admitted to NICU after $2 \mathrm{~h}$ of delivery were excluded from the analysis, because of the impact of hypothermia on neonatal morbidity and mortality[28-30]. Third, the infants without exposure to ACS were not included in this study, although we believed that the exclusion of infants who unexposed to ACS might not affect the rates of neonatal mortality and/or respiratory outcomes with the administration-to-birth interval of 2-7 d as a reference. Fourth, the risk of BPD could not be assessed in preterm infants who died before 36 wk postmenstrual age or transferred to another hospitals, which might lead to certain bias in the interpretation of BPD findings. However, it may not affect to the rates of surfactant use and the need for intubation/mechanical ventilation, which are employed in the early stage of preterm life, as well as the incidence of neonatal mortality. Fifth, as the study period spanned 7 years, some unmeasured risk factors and changes in clinical practice may occur, which can affect the rates of our primary and secondary outcomes. Lastly, the data of this study were collected from a single center, and we only included pregnant women of $<32$ wk GA. Therefore, our findings are not generalizable to the entire population. Although we adjusted the potential confounders that differed among groups, some unmeasured residual confounding factors are still existed due to the inadequate adjustment of baseline differences in the multivariate analysis.

\section{Conclusions And Clinical Implications}

This study demonstrates that preterm infants exposed to ACS $<12 \mathrm{~h}$ is associated with a higher risk of NRDS and neonatal mortality in preterm infants born at $24^{0 / 7}-31^{6 / 7}$ wk of gestation compared to those with the ACS-to-birth interval of $2-7 \mathrm{~d}$. This study also points out that the severity of NRDS could be reduced by ACS administration at least $12 \mathrm{~h}$ before delivery in preterm infants. A multicenter, prospective study is needed to assess the differences in ACS administration rates among preterm infants in the future. Well-designed randomized controlled trials should be conducted to verify the effects of ACS administration within $24 \mathrm{~h}$ on NRDS and respiratory support in larger population-based cohorts.

\section{Abbreviations}

ACS:Antenatal corticosteroids; RDS: Respiratory distress syndrome; NICU:Neonatal intensive care units; BPD:bronchopulmonary dysplasia; PPROM:preterm prelabor rupture of membranes; GA: Gestational age.

\section{Declarations}

\section{Acknowledgements}

We thank the all participants, as well as the doctors and nurses involved in this study. We also thank YM Tang (Division of Hematology,The Children's Hospital Zhejiang University School of Medicine,Zhejiang,China) for his help in the reviewed and revised the paper.

\section{Authors' contributions}

LXL designed the study, collected data, carried out initial analyses, drafted the initial paper, and reviewed and revised the paper. HJL, YJJ conceptualized and designed the study and reviewed and revised the paper. BMY collected data and reviewed and revised the paper.All authors approved the final paper as submitted and agree to be accountable for all aspects of the work.

\section{Funding}

No external funding for this paper.

\section{Availability of data and materials}

The datasets generated during the current study are not publicly available due to this study was a multicenter study, the agencies were keeping the data confidential but are available from the corresponding author on reasonable request. 


\section{Ethics approval and consent to participate}

Researchers confirm that all methods were performed in accordance with the relevant guidelines and regulations. This study was approved by the ethical committee of Shaoxing Maternity and Child Health Care Hospital. All participants provided written informed consent, and the ethics committee approved the procedures. If subjects were under 18 or illiterate, informed consent was obtained from their legal guardians.

\section{Consent for publication}

Not applicable.

\section{Competing interests}

The authors declare that they have no competing interests.

\section{Author details}

${ }^{1}$ Department of Neonatology, Shaoxing Maternity and Child Health Care Hospital, 305 East Street, Yuecheng District, Shaoxing, China.

\section{References}

1. Sweet DG, Carnielli V, Greisen G, Hallman M, Ozek E, Plavka R, et al. European Consensus Guidelines on the Management of Respiratory Distress Syndrome - 2016 Update. Neonatology. 2017;111:107-125.

2. Sweet DG, Carnielli V, Greisen G, Hallman M, Ozek E, Te Pas A, et al. European Consensus Guidelines on the Management of Respiratory Distress Syndrome - 2019 Update. Neonatology. 2019;115:432-450.

3. Association CSGfOaGoCM. Clinical diagnosis and treatment guidelines for premature delivery. Chin J Obstet Gynecol. 2014;49:481-485.

4. Committee Opinion No. 713: Antenatal Corticosteroid Therapy for Fetal Maturation. Obstet Gynecol. 2017;130:e102-e109.

5. Travers CP, Clark RH, Spitzer AR, Das A, Garite TJ, Carlo WA. Exposure to any antenatal corticosteroids and outcomes in preterm infants by gestational age: prospective cohort study. Bmj. 2017;356:j1039.

6. Norman M, Piedvache A, Børch K, Huusom LD, Bonamy AE, Howell EA, et al. Association of Short Antenatal Corticosteroid Administration-to-Birth Intervals With Survival and Morbidity Among Very Preterm Infants: Results From the EPICE Cohort. JAMA Pediatr. 2017;171:678-686.

7. Infants CSGfEPELBW. Antenatal corticosteroid administration in extremely preterm and extremely low birth weight infants and its effects on prognosis: a multicentre survey. Chin J Perinat Med. 2020;23:302-310.

8. Liebowitz M, Clyman RI. Antenatal Betamethasone: A Prolonged Time Interval from Administration to Delivery Is Associated with an Increased Incidence of Severe Intraventricular Hemorrhage in Infants Born before 28 Weeks Gestation. J Pediatr. 2016;177:114-120.e111.

9. Boghossian NS, McDonald SA, Bell EF, Carlo WA, Brumbaugh JE, Stoll BJ, et al. Association of Antenatal Corticosteroids With Mortality, Morbidity, and Neurodevelopmental Outcomes in Extremely Preterm Multiple Gestation Infants. JAMA Pediatr. 2016;170:593-601.

10. Battarbee AN, Ros ST, Esplin MS, Biggio J, Bukowski R, Parry S, et al. Optimal timing of antenatal corticosteroid administration and preterm neonatal and early childhood outcomes. Am J Obstet Gynecol MFM. 2020;2:100077.

11. Kuk JY, An JJ, Cha HH, Choi SJ, Vargas JE, Oh SY, et al. Optimal time interval between a single course of antenatal corticosteroids and delivery for reduction of respiratory distress syndrome in preterm twins. Am J Obstet Gynecol. 2013;209:256.e251-257.

12. Melamed N, Shah J, Soraisham A, Yoon EW, Lee SK, Shah PS, et al. Association Between Antenatal Corticosteroid Administration-to-Birth Interval and Outcomes of Preterm Neonates. Obstet Gynecol. 2015;125:1377-1384.

13. Gulersen M, Gyamfi-Bannerman C, Greenman M, Lenchner E, Rochelson B, Bornstein E. Time interval from late preterm antenatal corticosteroid administration to delivery and the impact on neonatal outcomes. Am J Obstet Gynecol MFM. 2021;3:100426.

14. Sekhavat L, Firouzabadi RD, Karbasi SA. Comparison of interval duration between single course antenatal corticosteroid administration and delivery on neonatal outcomes. J Turk Ger Gynecol Assoc. 2011;12:86-89.

15. Yasuhi I, Myoga M, Suga S, Sugimi S, Umezaki Y, Fukuda M, et al. Influence of the interval between antenatal corticosteroid therapy and delivery on respiratory distress syndrome. J Obstet Gynaecol Res. 2017;43:486-491.

16. Shao XM, Ye HM, Qiu XS. Practice of neonatology, 4th edition. People's Medical Publishing House. 2011.

17. Ikegami M, Polk D, Jobe A. Minimum interval from fetal betamethasone treatment to postnatal lung responses in preterm lambs. Am J Obstet Gynecol. 1996;174:1408-1413.

18. Norberg H, Kowalski J, Maršál K, Norman M. Timing of antenatal corticosteroid administration and survival in extremely preterm infants: a national population-based cohort study. Bjog. 2017;124:1567-1574.

19. Ushida T, Kotani T, Hayakawa M, Hirakawa A, Sadachi R, Nakamura N, et al. Antenatal corticosteroids and preterm offspring outcomes in hypertensive disorders of pregnancy: A Japanese cohort study. Sci Rep. 2020;10:9312. 
20. Dehaene I, De Coen K, Oostra A, Decruyenaere J, Roelens K, Smets K. Antenatal corticosteroids-to-birth interval in preterm birth. Acta Clin Belg. 2021;76:433-440.

21. Mulder EJ, de Heus R, Visser GH. Antenatal corticosteroid therapy: short-term effects on fetal behaviour and haemodynamics. Semin Fetal Neonatal Med. 2009;14:151-156.

22. Subtil D, Tiberghien P, Devos $P$, Therby D, Leclerc G, Vaast $P$, et al. Immediate and delayed effects of antenatal corticosteroids on fetal heart rate: a randomized trial that compares betamethasone acetate and phosphate, betamethasone phosphate, and dexamethasone. Am J Obstet Gynecol. 2003;188:524-531.

23. Süvari L, Helve OM, Kari MA, Turpeinen LU, Palojärvi PA, Leskinen MJ, et al. Glucocorticoids, sodium transport mediators, and respiratory distress syndrome in preterm infants. Pediatr Res. 2021;89:1253-1260.

24. Süvari L, Janér C, Helve O, Kaskinen A, Turpeinen U, Pitkänen-Argillander O, et al. Postnatal gene expression of airway epithelial sodium transporters associated with birth stress in humans. Pediatr Pulmonol. 2019;54:797-803.

25. Vermillion ST, Soper DE, Newman RB. Is betamethasone effective longer than 7 days after treatment? Obstet Gynecol. 2001;97:491-493.

26. Thébaud B, Goss KN, Laughon M, Whitsett JA, Abman SH, Steinhorn RH, et al. Bronchopulmonary dysplasia. Nat Rev Dis Primers. $2019 ; 5: 78$.

27. Travers CP, Carlo WA, McDonald SA, Das A, Bell EF, Ambalavanan N, et al. Mortality and pulmonary outcomes of extremely preterm infants exposed to antenatal corticosteroids. Am J Obstet Gynecol. 2018;218:130.e131-130.e113.

28. Bissinger RL, Annibale DJ. Thermoregulation in very low-birth-weight infants during the golden hour: results and implications. Adv Neonatal Care. 2010;10:230-238.

29. Ting JY, Synnes AR, Lee SK, Shah PS. Association of admission temperature and death or adverse neurodevelopmental outcomes in extremely lowgestational age neonates. J Perinatol. 2018;38:844-849.

30. Tay VY, Bolisetty S, Bajuk B, Lui K, Smyth J. Admission temperature and hospital outcomes in extremely preterm infants. J Paediatr Child Health. 2019;55:216-223.

\section{Tables}

Table 1

Baseline characteristics of the study population (interval from steroid therapy to delivery).

\begin{tabular}{|c|c|c|c|c|c|}
\hline \multirow[t]{2}{*}{ Characteristics } & ACS $₫ 24 \mathrm{~h}$ & $\operatorname{ACS} 1-2 \mathrm{~d}$ & ACS 2-7 d & ACS $\otimes 7 \mathrm{~d}$ & \multirow[t]{2}{*}{$p$ value } \\
\hline & $\mathrm{n}=264(37.39 \%)$ & $\mathrm{n}=83(11.76 \%)$ & $\mathrm{n}=292(41.36 \%)$ & $\mathrm{n}=67(9.49 \%)$ & \\
\hline \multicolumn{6}{|l|}{ Infant } \\
\hline GA at delivery, wk, (IQR) & $30.0(28.6,31.1)$ & $30.5(29.4,31.3)$ & $30.4(29.3,31.1)$ & $30.4(29.3,31.1)$ & 0.009 \\
\hline Birth weight, g, (IQR) & $1415(1230,1640)$ & $1550(1300,1730)$ & $1480(1235,1700)$ & $1520(1300,1700)$ & 0.052 \\
\hline Gender (n, \%), male & $141 / 264(53.41)$ & 49/83 (59.04) & $172 / 292(58.90)$ & $43 / 67(64.18)$ & 0.342 \\
\hline Twin $(n, \%)$ & $69 / 264(26.14)$ & $11 / 83(13.25)$ & $56 / 292(19.18)$ & $16 / 67(23.88)$ & 0.048 \\
\hline Duration of ventilation (d, IQR) & $10(2,23)$ & $7(0,14)$ & $7(0,20)$ & $4.5(1,13)$ & 0.01 \\
\hline Duration of hospitalization (d, IQR) & $31(20,42)$ & $28(22,38)$ & $30.5(22,40.5)$ & $30(22,39)$ & 0.85 \\
\hline ACS interval before delivery (h, IQR) & $4(1.5,11)$ & $34(27,42)$ & $76(62.5,102.5)$ & $264(209,360)$ & $\otimes 0.001^{* *}$ \\
\hline \multicolumn{6}{|l|}{ Matemal } \\
\hline $\operatorname{PPROM}(\mathrm{n}, \%)$ & $27 / 264(10.23)$ & $42 / 83(50.60)$ & $123 / 292(42.12)$ & $20 / 67(29.85)$ & $\nabla 0.001^{\star *}$ \\
\hline Mode of delivery ( $n, \%)$, vaginal & $130 / 264(49.24)$ & 25/83 (30.12) & 104/292 (35.62) & $20 / 67(29.85)$ & $\nabla 0.001^{\star *}$ \\
\hline Placenta previa $(\mathrm{n}, \%)$ & $16 / 264(6.06)$ & $5 / 83(6.02)$ & $19 / 292(6.51)$ & $12 / 67(17.91)$ & $0.019 *$ \\
\hline Placental abruption (n, \%) & $15 / 264(5.68)$ & $2 / 83(2.41)$ & $10 / 292(3.42)$ & $5 / 67(7.46)$ & 0.278 \\
\hline Gestational diabetes mellitus ( $\mathrm{n}, \%)$ & $35 / 264(13.26)$ & $14 / 83(16.87)$ & $38 / 292(13.01)$ & $6 / 67(8.96)$ & 0.579 \\
\hline Fetal intrauterine distress (n, \%) & $23 / 264(8.71)$ & 14/83 (16.87) & $32 / 292(10.96)$ & $8 / 67(11.94)$ & 0.214 \\
\hline Hypertension disorder in pregnant (n, \%) & $19 / 264(7.20)$ & 13/83 (15.66) & $47 / 292(16.10)$ & $9 / 67(13.43)$ & 0.007 \\
\hline
\end{tabular}

* $p \llbracket 0.05, * \star p \rrbracket 0.01$.

Abbreviations: ACS, antenatal corticosteroids; IQR, interquartile range; PPROM, preterm prelabor rupture of membranes. Data are analyzed by KruskalWallis $\mathrm{H}$ test or $\chi 2$ test. 
Relationships between ACS-to-birth intervals and neonatal outcomes.

\begin{tabular}{|c|c|c|c|c|c|c|c|c|c|c|c|c|}
\hline & \multicolumn{3}{|c|}{$\begin{array}{l}\text { ACS } 24 \mathrm{~h} \\
\mathrm{n}=264(37.39 \%)\end{array}$} & \multicolumn{3}{|c|}{$\begin{array}{l}\text { ACS 1-2d } \\
n=83(11.76 \%)\end{array}$} & \multicolumn{3}{|c|}{$\begin{array}{l}\text { ACS 2-7d } \\
n=292(41.36 \%)\end{array}$} & \multicolumn{3}{|l|}{$\begin{array}{l}\text { ACS>7d } \\
n=67(9.49 \%)\end{array}$} \\
\hline & \multirow[t]{2}{*}{ no./total (\%) } & \multicolumn{2}{|c|}{ OR $95 \% \mathrm{Cl}$} & \multirow[t]{2}{*}{ no./total (\%) } & \multicolumn{2}{|c|}{ OR $95 \% \mathrm{Cl}$} & \multirow[t]{2}{*}{ no./total (\%) } & \multicolumn{2}{|c|}{ OR $95 \% \mathrm{Cl}$} & \multirow[t]{2}{*}{ no./total (\%) } & \multicolumn{2}{|c|}{ OR $95 \% \mathrm{Cl}$} \\
\hline & & COR & AOR & & $\mathrm{COR}$ & AOR & & COR & AOR & & $\mathrm{COR}$ & AOR \\
\hline Death & $\begin{array}{l}28 / 263 \\
(10.6)\end{array}$ & $\begin{array}{l}3.0 \\
(1.5- \\
6.2)^{\star *}\end{array}$ & $\begin{array}{l}2.8 \\
(1.1- \\
6.8)^{\star}\end{array}$ & $\begin{array}{r}3 / 83 \\
(3.6)\end{array}$ & $\begin{array}{l}0.9 \\
(0.3- \\
3.5)\end{array}$ & $\begin{array}{l}1.5 \\
(0.4- \\
6.1)\end{array}$ & $\begin{array}{l}11 / 292 \\
(3.8)\end{array}$ & - & - & $\begin{array}{r}2 / 67 \\
(3.0)\end{array}$ & $\begin{array}{l}0.8 \\
(0.2- \\
3.6)\end{array}$ & $\begin{array}{l}1.3 \\
(0.2- \\
7.1)\end{array}$ \\
\hline Surfactant/mechanical & $\begin{array}{l}106 / 264 \\
(40.2)\end{array}$ & $\begin{array}{l}2.7 \\
(1.8- \\
3.9)^{* *}\end{array}$ & $\begin{array}{l}2.8 \\
(1.7- \\
4.4)^{* k}\end{array}$ & $\begin{array}{r}19 / 83 \\
(22.9)\end{array}$ & $\begin{array}{l}1.2 \\
(0.7- \\
2.2)\end{array}$ & $\begin{array}{l}1.6 \\
(0.8- \\
3.1)\end{array}$ & $\begin{array}{c}58 / 292 \\
(19.9)\end{array}$ & - & - & $\begin{array}{r}16 / 67 \\
(23.9)\end{array}$ & $\begin{array}{l}1.3 \\
(0.7- \\
2.4)\end{array}$ & $\begin{array}{l}1.2 \\
(0.6- \\
2.5)\end{array}$ \\
\hline NRDS & $\begin{array}{l}174 / 264 \\
(65.9)\end{array}$ & $\begin{array}{l}2.3 \\
(1.6- \\
3.3)^{\star *}\end{array}$ & $\begin{array}{l}1.8 \\
(1.2- \\
2.7)^{* *}\end{array}$ & $\begin{array}{r}40 / 83 \\
(48.2)\end{array}$ & $\begin{array}{l}1.1 \\
(0.7- \\
1.8)\end{array}$ & $\begin{array}{l}1.4 \\
(0.8- \\
2.4)\end{array}$ & $\begin{array}{l}133 / 292 \\
(45.6)\end{array}$ & - & - & $\begin{array}{c}29 / 67 \\
(43.3)\end{array}$ & $\begin{array}{l}0.9 \\
(0.5- \\
1.6)\end{array}$ & $\begin{array}{l}0.8 \\
(0.4- \\
1.4)\end{array}$ \\
\hline Surfactant use & $\begin{array}{l}98 / 264 \\
(37.1)\end{array}$ & $\begin{array}{l}2.9 \\
(1.9- \\
4.2)^{\star *}\end{array}$ & $\begin{array}{l}2.7 \\
(1.7- \\
4.4)^{* *}\end{array}$ & $\begin{array}{l}15 / 83 \\
(18.1)\end{array}$ & $\begin{array}{l}1.1 \\
(0.6- \\
2.0)\end{array}$ & $\begin{array}{l}1.4 \\
(0.7- \\
2.8)\end{array}$ & $\begin{array}{l}50 / 292 \\
(17.1)\end{array}$ & - & - & $\begin{array}{l}15 / 67 \\
(22.4)\end{array}$ & $\begin{array}{l}1.4 \\
(0.7- \\
2.7)\end{array}$ & $\begin{array}{l}1.3 \\
(0.6- \\
2.7)\end{array}$ \\
\hline Intubation at birth & $\begin{array}{l}41 / 264 \\
(15.5)\end{array}$ & $\begin{array}{l}2.5 \\
(1.4- \\
4.4)^{\star \star}\end{array}$ & $\begin{array}{l}1.9 \\
(1.0- \\
3.7)^{*}\end{array}$ & $\begin{array}{r}7 / 83 \\
(8.4)\end{array}$ & $\begin{array}{l}1.3 \\
(0.5- \\
3.1)\end{array}$ & $\begin{array}{l}1.6 \\
(0.6- \\
4.3)\end{array}$ & $\begin{array}{l}20 / 292 \\
(6.9)\end{array}$ & - & - & $\begin{array}{l}8 / 67 \\
(11.9)\end{array}$ & $\begin{array}{l}1.8 \\
(0.8- \\
4.4)\end{array}$ & $\begin{array}{l}1.8 \\
(0.7- \\
4.7)\end{array}$ \\
\hline Mechanical ventilation & $\begin{array}{c}50 / 264 \\
(18.9)\end{array}$ & $\begin{array}{l}2.0 \\
(1.3- \\
3.3)^{\star \star}\end{array}$ & $\begin{array}{l}1.9 \\
(1.1- \\
3.4)^{*}\end{array}$ & $\begin{array}{l}9 / 83 \\
(10.8)\end{array}$ & $\begin{array}{l}1.1 \\
(0.5- \\
2.3)\end{array}$ & $\begin{array}{l}1.3 \\
(0.6- \\
3.1)\end{array}$ & $\begin{array}{c}30 / 292 \\
(10.3)\end{array}$ & - & - & $\begin{array}{l}9 / 67 \\
(13.4)\end{array}$ & $\begin{array}{l}1.4 \\
(0.6- \\
3.0)\end{array}$ & $\begin{array}{l}1.5 \\
(0.6- \\
3.6)\end{array}$ \\
\hline BPD & $\begin{array}{l}29 / 228 \\
(12.7)\end{array}$ & $\begin{array}{l}1.2 \\
(0.7- \\
2.0)\end{array}$ & $\begin{array}{l}1.3 \\
(0.7- \\
2.6)\end{array}$ & $\begin{array}{r}7 / 76 \\
(9.2)\end{array}$ & $\begin{array}{l}0.8 \\
(0.3- \\
1.9)\end{array}$ & $\begin{array}{l}1.4 \\
(0.5- \\
3.7)\end{array}$ & $\begin{array}{l}30 / 275 \\
(10.9)\end{array}$ & - & - & $\begin{array}{r}2 / 67 \\
(3.1)\end{array}$ & $\begin{array}{l}0.3 \\
(0.1- \\
1.1)\end{array}$ & $\begin{array}{l}0.4 \\
(0.1- \\
1.8)\end{array}$ \\
\hline
\end{tabular}

${ }^{*} p \otimes 0.05,{ }^{*} p \otimes 0.01$.

Abbreviations: COR; crude odds ratio; AOR, adjusted odds ratio; BPD: bronchopulmonary dysplasia; $\mathrm{Cl}$, confidence interval; NRDS: newborn respiratory distress syndrome. Data were analyzed by univariate and multivariate logistic regression analyses.

AORs: adjusted for maternal age, birth weight, gestational age at birth, premature rupture of membranes $>18 \mathrm{~h}$, mode of delivery, placenta previa hypertension disorders in pregnancy, the infants exposed to ACS within 2-7 d before birth were regarded as a reference group.

Table 3

Association between ACS-to-birth interval of $<24 \mathrm{~h}$ and neonatal outcomes.

\begin{tabular}{|c|c|c|c|c|c|c|}
\hline & \multicolumn{2}{|l|}{ ACS $₫ 6 \mathrm{~h}$} & \multicolumn{2}{|l|}{ ACS 6-12 h } & \multicolumn{2}{|l|}{ ACS $12-24 \mathrm{~h}$} \\
\hline & $n=153$ & & $\mathrm{n}=50$ & & $n=61$ & \\
\hline & no./total (\%) & AOR $95 \% \mathrm{Cl}$ & no./total (\%) & AOR $95 \% \mathrm{Cl}$ & no./total (\%) & AOR $95 \% \mathrm{Cl}$ \\
\hline Death & 19/153 (12.4) & $3.2(1.2-8.5) *$ & 8/49 (16.33) & $6.1(1.8-20.1)^{\star \star}$ & $1 / 61(1.6)$ & $0.4(0.1-3.7)$ \\
\hline NRDS & 110/153 (71.9) & $2.4(1.4-3.8) \star \star$ & $30 / 50(60.0)$ & $1.2(0.6-2.4)$ & $34 / 61(55.7)$ & $1.6(0.8-2.9)$ \\
\hline Surfactcant use & $65 / 153(42.5)$ & $3.5(2.0-6.0) * *$ & $19 / 50(38.0)$ & $2.5(1.2-5.4)^{\star}$ & $14 / 61(22.9)$ & $1.7(0.8-3.6)$ \\
\hline Intubation in delivery room & $31 / 153$ (20.3) & $2.6(1.3-5.2) * \star$ & $7 / 50(14.0)$ & $1.6(0.6-4.4)$ & $3 / 61(4.9)$ & $0.7(0.2-2.5)$ \\
\hline Mechanical ventilation & $37 / 153(24.2)$ & $2.8(1.5-5.4) * \star$ & $9 / 50(18.0)$ & $1.9(0.8-4.7)$ & $4 / 61(6.6)$ & $0.7(0.2-2.1)$ \\
\hline BPD & $17 / 129(13.2)$ & $1.5(0.6-3.3)$ & $5 / 40(12.5)$ & $1.1(0.3-3.7)$ & 7/59 (11.9) & $1.3(0.5-3.5)$ \\
\hline Surfactant /mechanical & $70 / 153(45.8)$ & $3.7(2.1-6.3) \star \star$ & $21 / 50(42.0)$ & $2.7(1.3-5.8) \star \star$ & $15 / 61(24.6)$ & $1.6(0.8-3.3)$ \\
\hline
\end{tabular}

* $p \llbracket 0.05, * * p \rrbracket 0.01$.

Abbreviations: AOR, adjusted odds ratio; BPD: bronchopulmonary dysplasia; Cl, confidence interval; NRDS: newborn respiratory distress syndrome. Data were analyzed by multivariate logistic regression analyses.

AORs adjusted for birth weight, gestational age at birth, premature rupture of membranes $>18 \mathrm{~h}$, mode of delivery, placenta previa and hypertension disorders in pregnancy, multivariable logistic analysis, the infants exposed to ACS within 2-7 d before birth were regarded as a reference group. 
Figures

Figure 1

Description of the study groups.

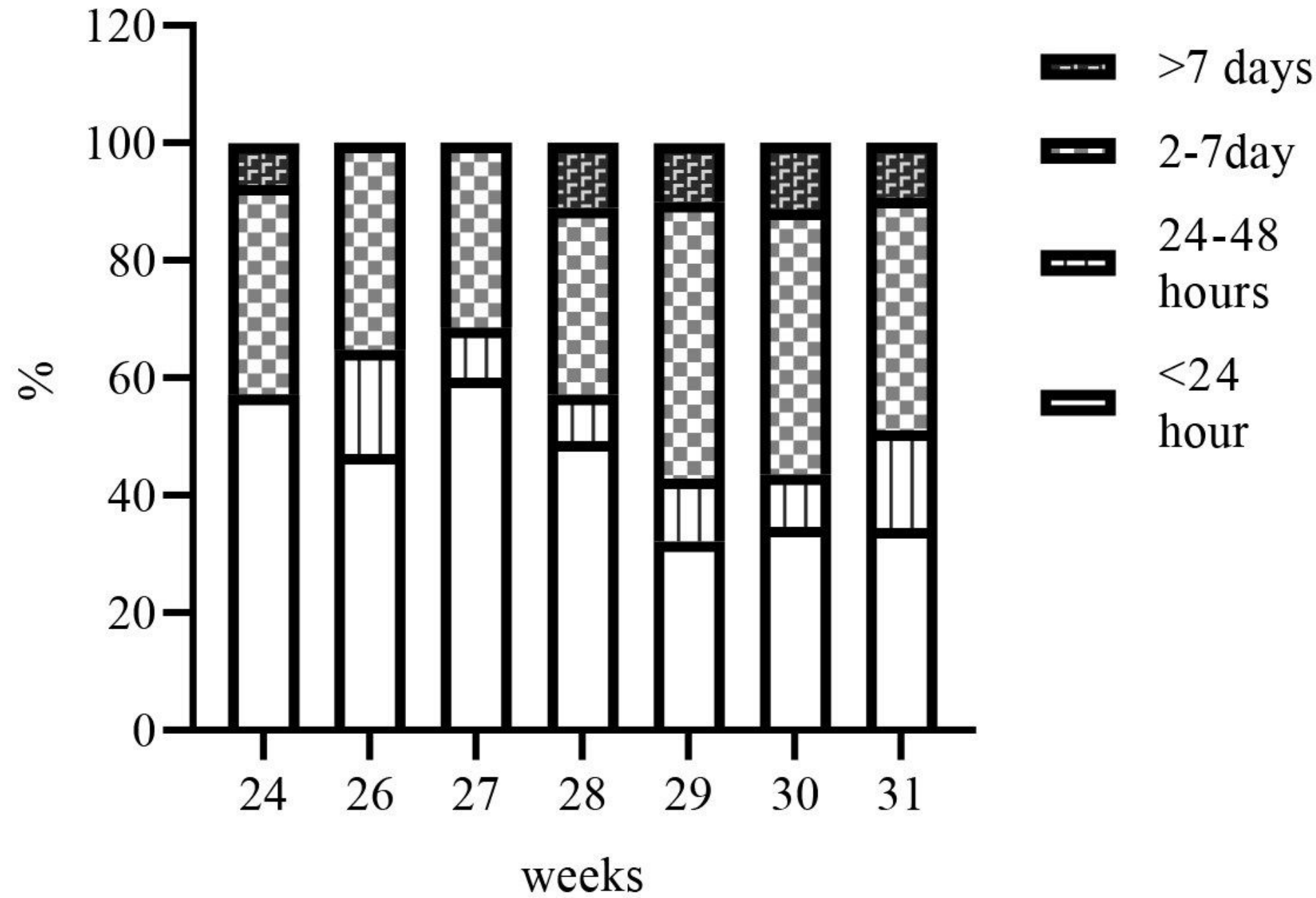

Figure 2

Distribution of the gestational age at birth in the four groups. 